\title{
Development of Models for Predicting Global Solar Radiation in Minna, Nigeria using Meteorological Data
}

\author{
Okonkwo G.N. ${ }^{1}$ And Nwokoye A.O.C. ${ }^{2}$ \\ ${ }^{I}$ Department of Science Laboratory Technology, The Federal Polytechnic, Bida. Niger State. \\ ${ }^{2}$ Department of Physics and Industrial Physics, Nnamdi Azikiwe University, Awka.
}

\begin{abstract}
The monthly mean daily meteorological data measured in Minna $\left(09.65^{\circ} \mathrm{N}, 06.47^{\circ} \mathrm{E}\right)$ for a period of thirteen years (2000 - 2012) were obtained with permission from Nigerian Meteorological Agency, Minna. These data, which comprised of Gunn-Bellani solar radiation, sunshine hour duration, relative humidity, rainfall, wind speed, maximum and minimum air temperatures were analysed based on Angstrom-Prescott model to generate several models (equations) for predicting global solar radiation in Minna. These models were subjected to statistical error test methods of the mean bias error (MBE), root mean square error (RMSE), mean percentage error (MPE) and paired sample test ( $T$ - test) to determine the best-performed model in predicting global solar radiation for all the months of the year in Minna. Based on the highest values of correlation coefficient, $R$, coefficient of determination, $R^{2}$ and least value of $R M S E$, the multivariable model that correlates the global solar radiation with sunshine hour duration, relative humidity, rainfall, wind speed, temperature ratio and the product of these parameters, proved to be the best model by giving the best performance from January to December. This model is therefore recommended for utilization by designers and engineers of solar energy systems in Minna and other localities having similar weather patterns.
\end{abstract}

Keywords: Angstrom-Prescott model, global solar radiation, sunshine hours, relative humidity, rainfall, wind speed, temperature ratio.

\section{Introduction}

Global solar radiation is the total solar radiation falling on a horizontal surface [1]. The amount of the global solar radiation received at a place per day, varies significantly with its geographical location, atmospheric conditions and time of the day. It is therefore important to know, at least, the average amount of the global solar radiation received at a particular location, before selecting or designing suitable solar energy system for that location. The best method for knowing the amount of global solar radiation is by direct measurement using an instrument called pyranometer.

However, due to cost of the equipment and the required expertise, direct measurement of solar radiation is carried out only at few designated locations such as international airport facilities and weather stations. For the locations where direct measurements are not done, empirical models (in form of regression equations) have been used to estimate the global solar radiation. This is achieved by correlating the global solar radiation with the meteorological (met) parameters (such as Gunn-Bellani solar radiation and sunshine hour duration) measured at the place of interest.

In the past, a large number of researchers have used Angstrom-type correlation model involving one or more met parameters (in a linear, multilinear, quadratic or cubic equations) to estimate the global solar radiation on a horizontal surface [2-13].

The objective of this paper is to develop Angstrom-type linear and multi-linear regression models using several met data, to predict the total solar radiation falling on a horizontal surface in Minna. The results of these models are also tested for error using the statistical test method of mean bias error (MBE), root mean square error (RMSE), and mean Percentage error (MPE), to select the best-performed model for Minna.

\section{Materials And Methods}

Gunn-Bellani solar radiation, sunshine hour duration, wind speed, relative humidity, rainfall, maximum and minimum temperature data measured for thirteen years $(2000$ - 2012) were obtained from Minna airport. The Gunn-Bellani solar radiation data was converted to $\mathrm{MJm}^{-2} \mathrm{day}^{-1}$ using a conversion factor of 1.216 (MJm ${ }^{2}$ day $^{-1}$ ) according to [14].

The converted Gunn-Bellani data were correlated with the other met data using the Angstrom-Prescott equations to develop single and multivariable correlation models for estimating the global solar radiation in Minna. The regression coefficients and error comparison tests were obtained with the computer programme, IBM SPSS 20. The models were developed in such a way as to relate with one another. The Angstrom equation modified by [15] is expressed as: 
$\frac{\bar{H}_{M}}{\bar{H}_{O}}=a+b\left(\frac{\bar{n}}{\bar{N}}\right)$

where, a and b are regression constants, $\bar{n}$ and $\bar{N}$ are the monthly mean daily bright sunshine hours and the maximum possible monthly mean daily sunshine hours (or the day length), respectively, $\bar{H}_{M}$ is the measured monthly mean daily global radiation, $\bar{H}_{O}$ is the monthly mean extraterrestrial solar radiation on horizontal surface, given by [16] as follows:

$\bar{H}_{O}=\frac{24}{\pi} I_{s c} E_{o}\left(\frac{\pi}{180} \omega_{s} \sin \varphi \sin \delta+\cos \varphi \cos \delta \sin \omega_{s}\right)$

where: $\mathrm{I}_{\mathrm{sc}}$ is the solar constant, $\mathrm{E}_{\mathrm{o}}$ is the eccentricity correction factor, $\varphi$ is the latitude angle, $\delta$ is the solar declination and $w_{s}$ is the hour angle. The expressions for $\mathrm{I}_{\mathrm{sc}}, \mathrm{E}_{\mathrm{o}}, \delta$ and $\omega_{s}$ are also given by [16] as:

$I_{s c}=\frac{1367 * 3600}{1000000} \mathrm{MJm}^{-2} \mathrm{day}^{-1}$

$E_{o}=1+0.033 \cos \left(\frac{360 N}{365}\right)$

$\delta=23.45 \sin \left(360\left(\frac{N+284}{365}\right)\right)$

where: $\mathrm{N}$ is the characteristic day number for each month.

$w_{s}=\cos ^{-1}(-\tan \varphi \tan \delta)$

The mean day length $\bar{N}$ is expressed as:

$\bar{N}=\frac{2}{15} w_{S}$

$\frac{\bar{H}_{M}}{\bar{H}_{O}}$ is the clearness index while $\frac{\bar{n}}{\bar{N}}$ is the fraction of sunshine duration.

The expressions for the error test indicators, MBE $\left(\mathrm{MJm}^{-2} \mathrm{day}^{-1}\right), \operatorname{RMSE}\left(\mathrm{MJm}^{-2} \mathrm{day}^{-1}\right)$, and MPE (\%) as stated by [17] are:

$M B E=\frac{\left[\Sigma\left(\bar{H}_{i, \text { cal }}-\bar{H}_{i, \text { meas }}\right)\right]}{n}$

$R M S E=\left[\frac{\sum\left(\bar{H}_{i, \text { cal }}-\bar{H}_{i, \text { meas }}\right)^{2}}{n}\right]^{1 / 2}$

MPE $=\frac{\left[\sum\left(\frac{\bar{H}_{i, \text { meas }} \bar{H}_{i, \text { cal }}}{\bar{H}_{i, \text { meas }}} \times 100\right)\right]}{n}$

where $\bar{H}_{i, \text { cal }}$ and $\bar{H}_{i, \text { meas }}$ are the ith calculated and measured values respectively, of solar radiation, $\mathrm{n}$ is the total number of observations.

Table 1. Monthly mean daily meteorological data for Minna

\begin{tabular}{|c|c|c|c|c|c|c|c|c|c|c|c|c|}
\hline Month & $\begin{array}{l}\bar{T}_{\max } \\
\left({ }^{\circ} \mathrm{C}\right)\end{array}$ & $\begin{array}{l}\bar{T}_{\min } \\
\left({ }^{\circ} \mathrm{C}\right)\end{array}$ & (日) & $\bar{R}$ & $\begin{array}{c}\bar{W} \\
\left(m s^{-1}\right)\end{array}$ & $\frac{\overline{R H}}{100}$ & $\begin{array}{c}\bar{n} \\
(\mathrm{hrs})\end{array}$ & $\begin{array}{c}\bar{N} \\
\text { (hrs) }\end{array}$ & $\begin{array}{l}\bar{n} \\
\overline{\bar{N}}\end{array}$ & $\begin{array}{c}\bar{H}_{M} \\
\left(\mathrm{MJm}^{-2} \text { day }\right. \\
\left.{ }^{1}\right)\end{array}$ & $\begin{array}{c}\bar{H}_{O} \\
\left(\mathrm{MJm}^{-2} \text { day }\right. \\
\left.{ }^{1}\right)\end{array}$ & $\begin{array}{l}\bar{K}_{T} \\
=\frac{\bar{H}_{M}}{\bar{H}_{O}}\end{array}$ \\
\hline Jan. & 34.6 & 20.6 & 0.60 & 0.0 & 8.9 & 0.32 & 6.7 & 11.5 & 0.5866 & 16.5 & 32.1 & 0.5137 \\
\hline Feb. & 37.2 & 23.3 & 0.63 & 0.0 & 8.7 & 0.33 & 7.6 & 11.7 & 0.6456 & 17.3 & 34.6 & 0.5013 \\
\hline Mar. & 38.7 & 25.6 & 0.66 & 0.0 & 7.5 & 0.40 & 7.1 & 12.0 & 0.5917 & 18.3 & 37.0 & 0.4953 \\
\hline Apr. & 36.8 & 25.3 & 0.69 & 2.1 & 9.2 & 0.59 & 7.4 & 12.2 & 0.6047 & 18.3 & 37.9 & 0.4825 \\
\hline May & 33.8 & 24.1 & 0.71 & 4.2 & 10.0 & 0.72 & 7.3 & 12.5 & 0.5893 & 17.5 & 37.4 & 0.4664 \\
\hline Jun. & 31.3 & 22.5 & 0.72 & 5.8 & 9.9 & 0.79 & 5.7 & 12.6 & 0.4557 & 16.2 & 36.8 & 0.4409 \\
\hline Jul. & 29.8 & 22.1 & 0.74 & 7.7 & 7.6 & 0.84 & 4.9 & 12.5 & 0.3883 & 15.0 & 37.0 & 0.4060 \\
\hline Aug. & 28.9 & 22.0 & 0.76 & 8.1 & 7.6 & 0.86 & 4.3 & 12.3 & 0.3483 & 14.4 & 37.5 & 0.3830 \\
\hline Sep. & 30.0 & 21.6 & 0.72 & 8.7 & 9.6 & 0.84 & 6.1 & 12.0 & 0.5028 & 16.7 & 37.1 & 0.4496 \\
\hline Oct. & 31.9 & 21.9 & 0.69 & 3.8 & 8.5 & 0.78 & 7.4 & 11.8 & 0.6245 & 18.0 & 35.1 & 0.5125 \\
\hline Nov. & 35.1 & 20.5 & 0.58 & 0.0 & 6.5 & 0.54 & 8.9 & 11.5 & 0.7732 & 18.4 & 32.6 & 0.5655 \\
\hline Dec. & 35.7 & 19.8 & 0.56 & 0.0 & 7.7 & 0.38 & 7.9 & 11.4 & 0.6943 & 16.6 & 31.2 & 0.5325 \\
\hline
\end{tabular}

\section{Results And Discussion}

In "Table" 1 , it was observed that the highest and lowest temperature values were measured in the months of March and December, respectively. It was also shown that the highest and lowest values of the fraction of sunshine occurred in the month of November and August, respectively. The high value of the fraction of sunshine could be attributed to the very high mean daily sunshine hours obtained due to a high clearness index in the month of November [12]. This was also the case of the global solar radiation which was highest in November and lowest in August.

"Table" 2 is the list of the regression equations (as well as their regression constants) used for this study. Models 1 and 2 are one-parameter linear and quadratic regression with fraction of sunshine, respectively. Model 3 is a two-parameter linear regression with fraction of sunshine and temperature ratio. Model 4 is a multi- 
linear three-parameter regression with fraction of sunshine, minimum temperature and rainfall. Model 5 is a multi-linear four-parameter regression with fraction of sunshine, rainfall, relative humidity and temperature ratio. Model 6 is a multi-linear five-parameter regression with fraction of sunshine, rainfall, wind speed, relative humidity and temperature ratio. Model 7 is a multi-linear regression with fraction of sunshine $\left(\frac{\bar{n}}{\bar{N}}\right)$, rainfall, wind speed, relative humidity, temperature ratio and product of these parameters. respectively.

The regression constants obtained for models 1 and 2 agree with the works of [4] and [9],

Table 2. Regression equations (models) and their constants

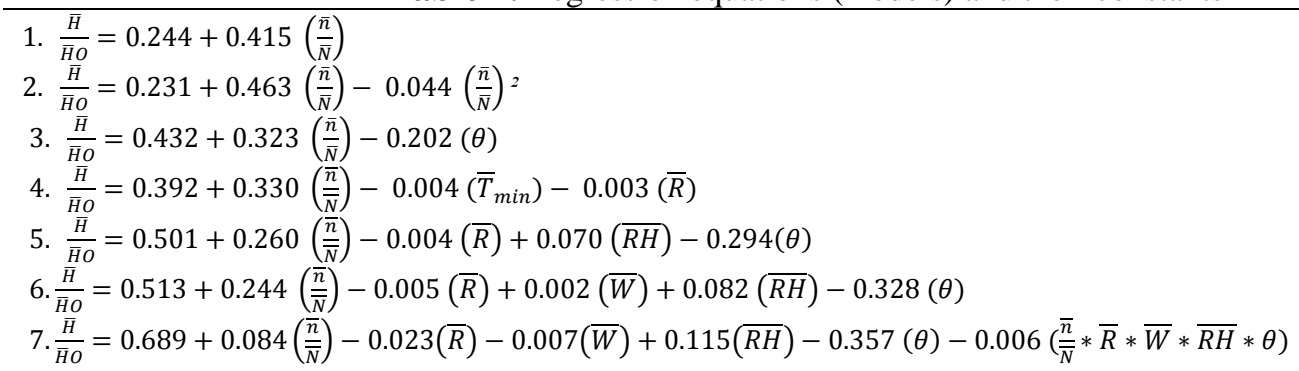

"Table" 3 shows the error test result of the developed model. It is observed that model 2 yielded the lowest MBE and MPE values followed by models 4 and 7. Again, model 2 has the highest P-value followed by models 4 and 7. On the other hand, model 7 yielded the lowest RMSE value followed by models 4, 5 and 6. Model 1 has the highest RMSE value followed by models 2 and 3. It is also evident that model 7 has the highest $\mathrm{R}$ and $\mathrm{R}^{2}$ values. The P-value (T-Test) also indicates that the variance between the measured solar radiation and model 7 is not significant. Its MBE and MPE values are also low.

Table 3. Statistical indicator of the models

\begin{tabular}{|c|c|c|c|c|c|c|}
\hline Models & $\mathrm{R}$ & $\mathrm{R}^{2}$ & $\mathrm{MBE}$ & RMSE & MPE & P-value (T-TEST) \\
\hline 1 & 0.972 & 0.945 & 0.021357 & 0.413396 & -0.11042 & 0.855 \\
\hline 2 & 0.972 & 0.945 & 0.002524 & 0.412416 & 0.00574 & 0.979 \\
\hline 3 & 0.982 & 0.964 & 0.019219 & 0.334664 & -0.14382 & 0.839 \\
\hline 4 & 0.985 & 0.970 & 0.006022 & 0.311651 & -0.08908 & 0.945 \\
\hline 5 & 0.985 & 0.970 & 0.057473 & 0.315211 & -0.38953 & 0.534 \\
\hline 6 & 0.985 & 0.971 & 0.094067 & 0.318818 & -0.59415 & 0.326 \\
\hline 7 & 0.993 & 0.985 & 0.009276 & 0.249355 & -0.09632 & 0.887 \\
\hline
\end{tabular}

Figs. "1 -7 " show the comparison plots between the measured and predicted global solar radiation over the twelve months of the year. From the plots, it was observed that models 1 and 2 are fit for predicting solar radiation in Minna except for the months of January and May. It was evident that models $3-7$ could be used in predicting solar radiation to a very good approximation in Minna, from January - December. However, model 7 has the closest relationship with the measured solar radiation for all the months of the year. Therefore, model 7 is the best model for predicting the global solar radiation in Minna. 


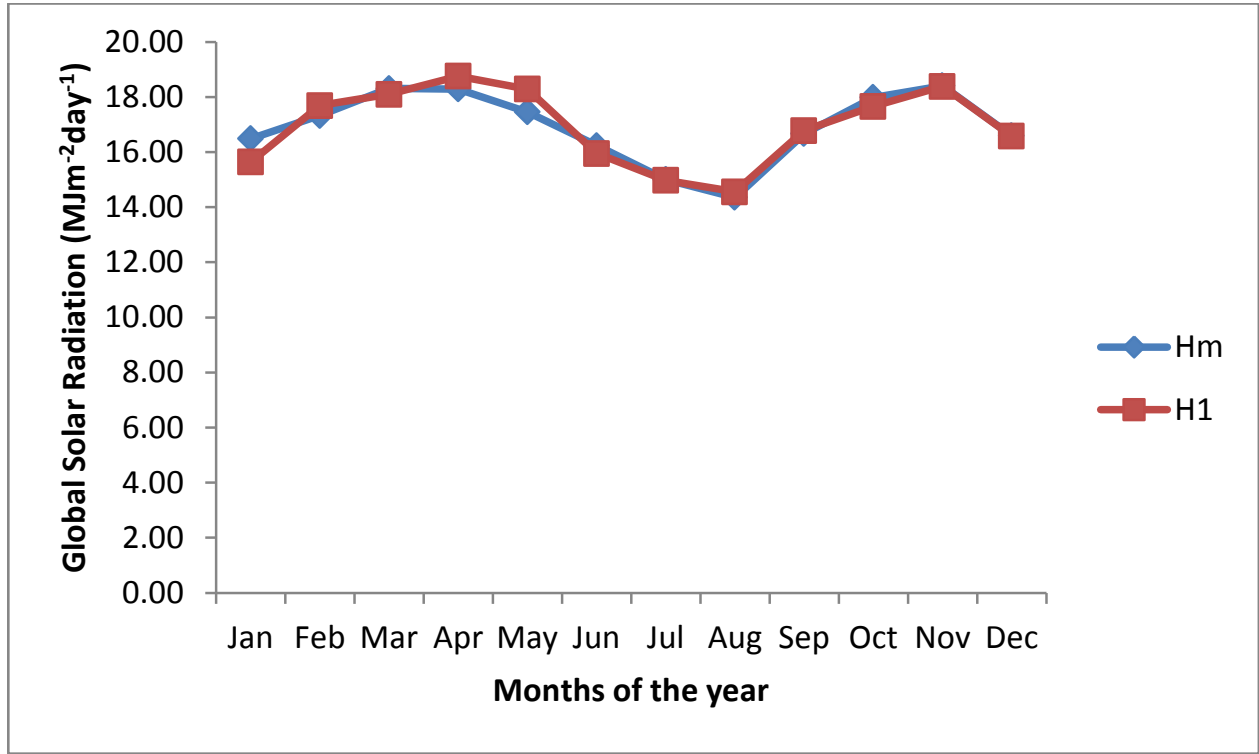

Figure 1.Comparison between measured solar radiation $(\mathrm{Hm})$ and predicted global solar radiation $(\mathrm{H} 1)$.

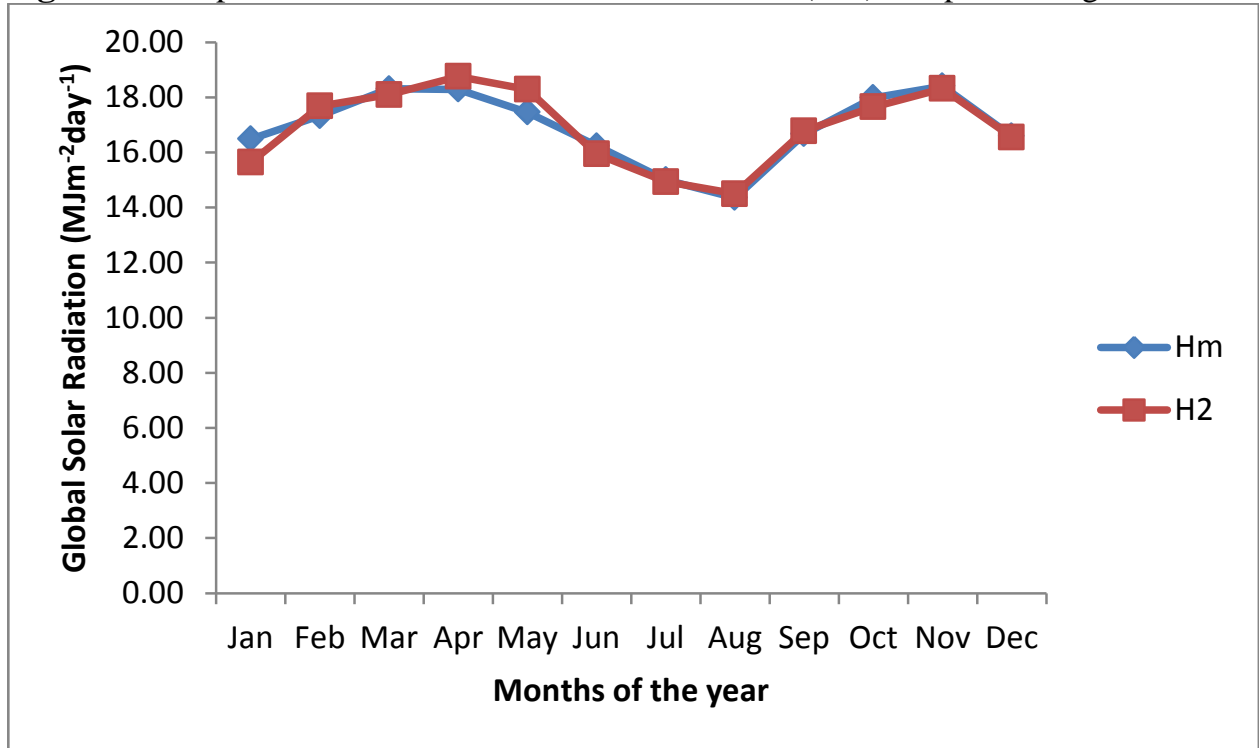

Figure 2.Comparison between measured solar radiation $(\mathrm{Hm})$ and predicted global solar radiation $(\mathrm{H} 2)$.

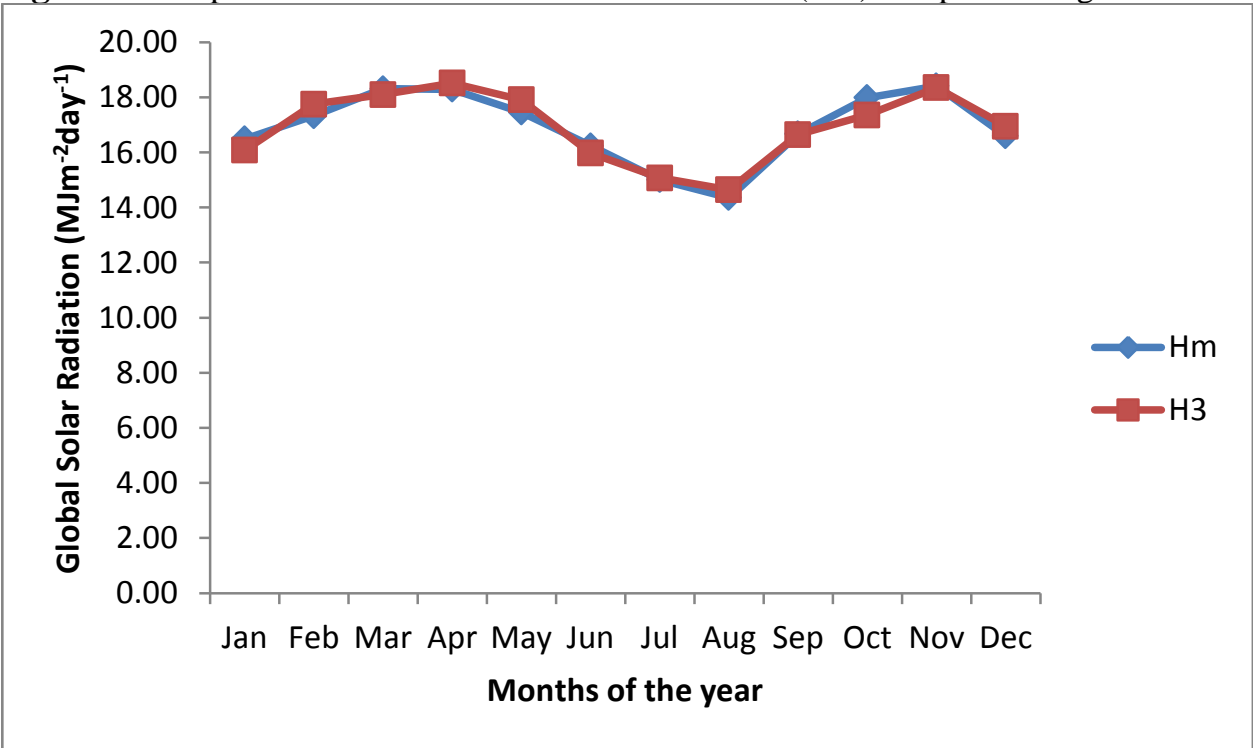

Figure 3.Comparison between measured solar radiation $(\mathrm{Hm})$ and predicted global solar radiation $(\mathrm{H} 3)$ 


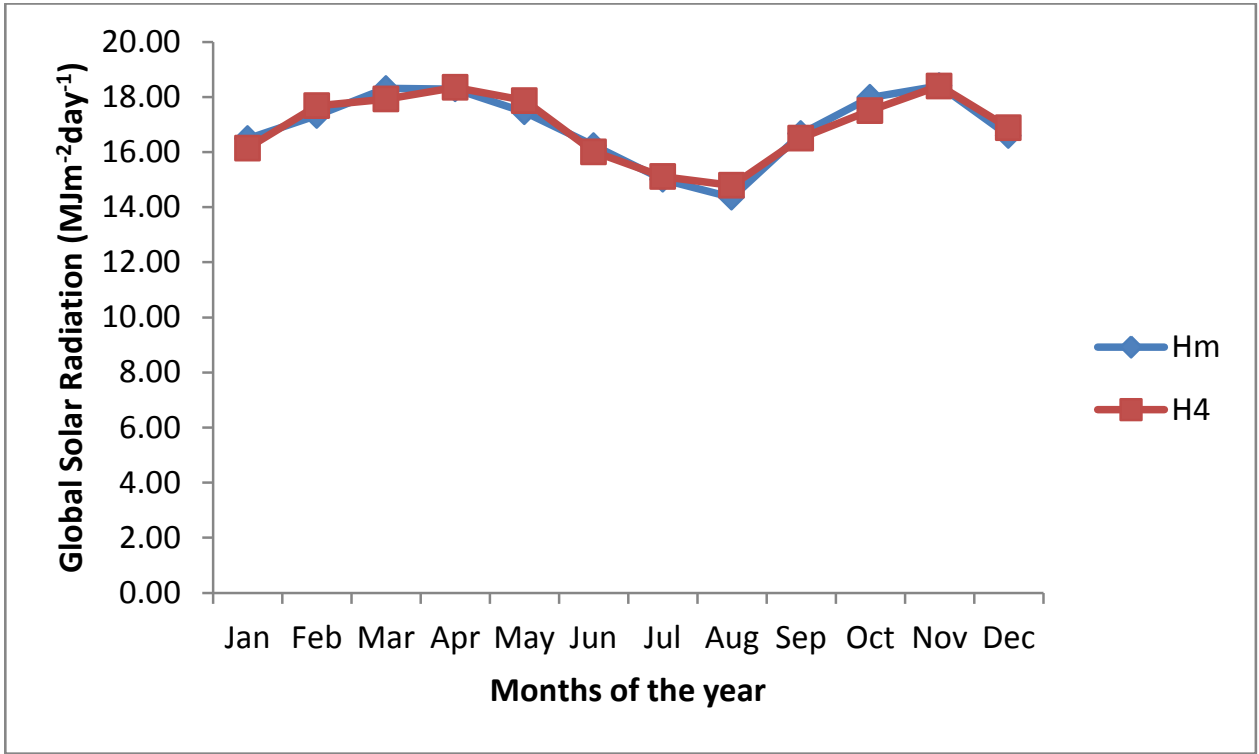

Figure 4.Comparison between measured solar radiation $(\mathrm{Hm})$ and predicted global solar radiation $(\mathrm{H} 4)$.

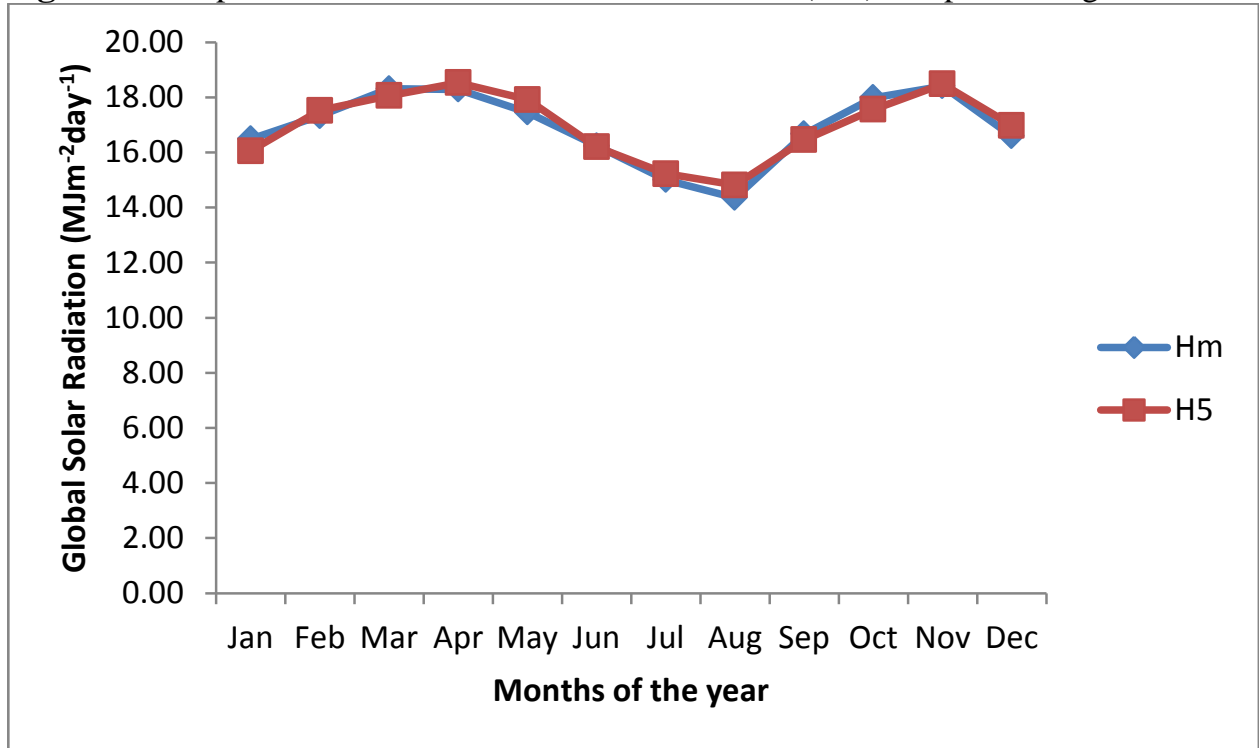

Figure 5.Comparison between measured solar radiation (Hm) and predicted global solar radiation (H5).

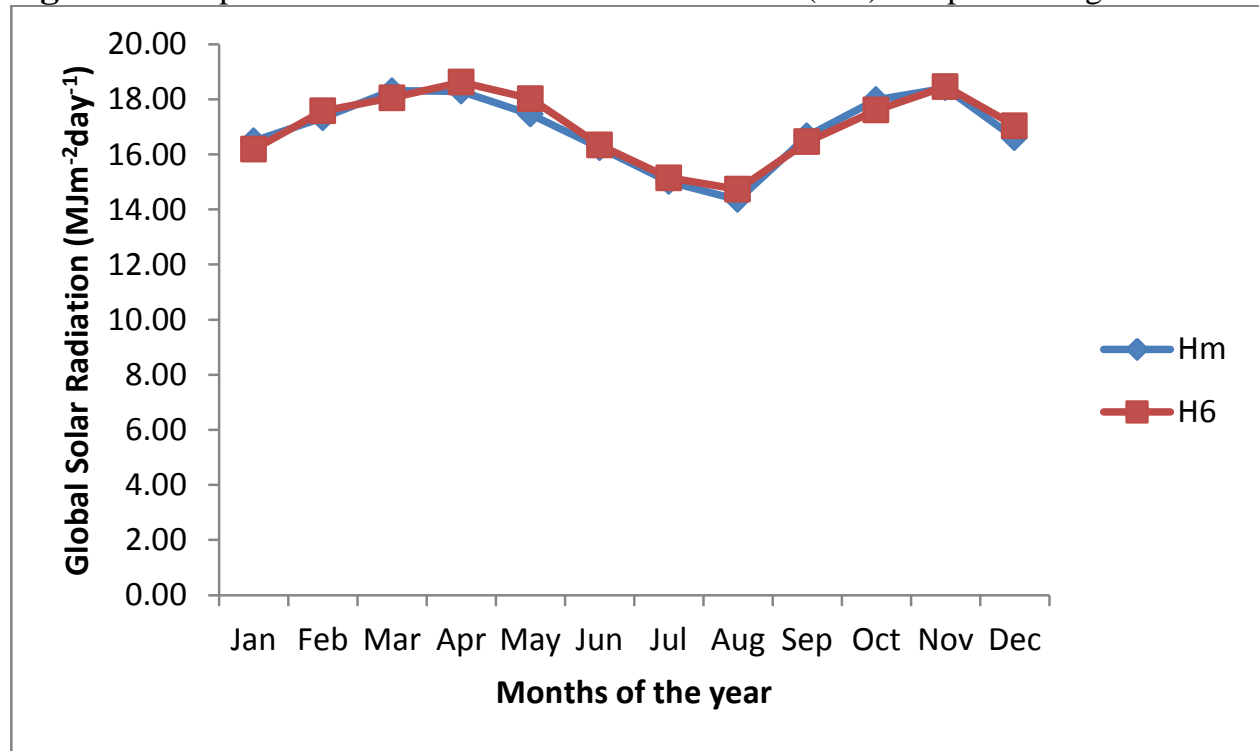

Figure 6.Comparison between measured solar radiation $(\mathrm{Hm})$ and predicted global solar radiation (H6). 


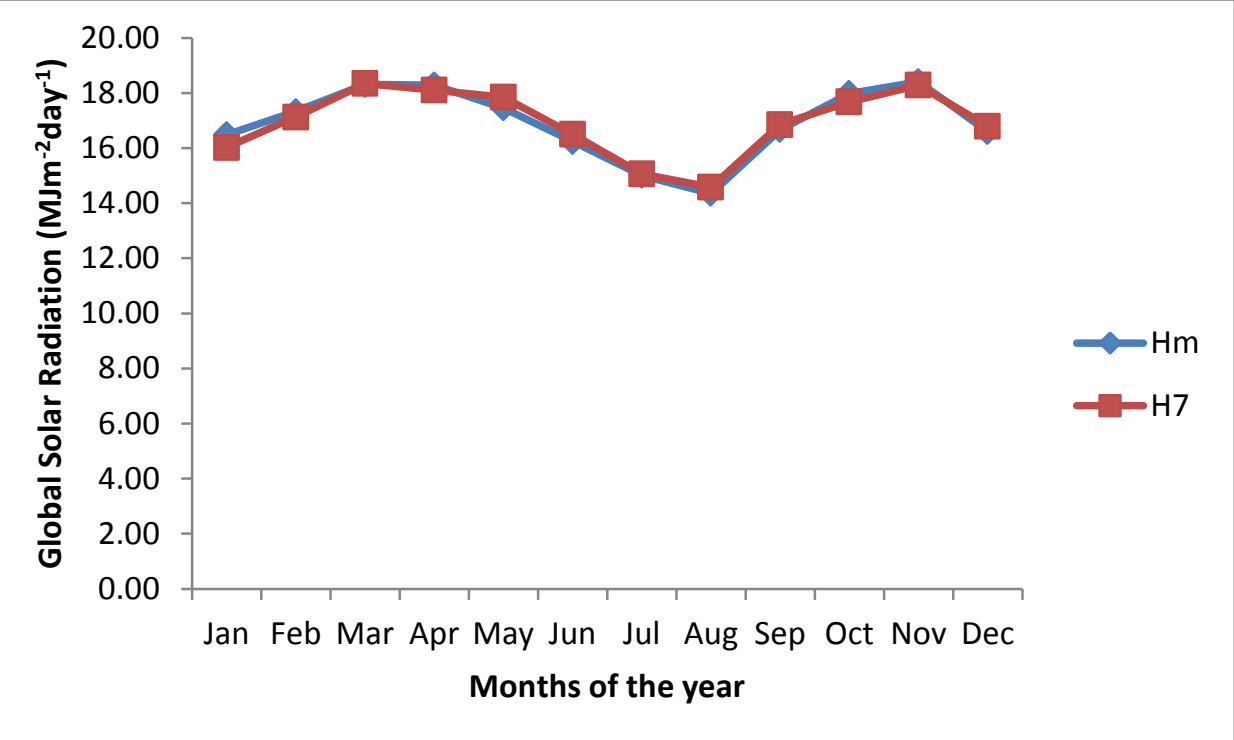

Figure 7.Comparison between measured solar radiation $(\mathrm{Hm})$ and predicted global solar radiation $(\mathrm{H} 7)$.

\section{Conclusion}

Seven models ("Table" 2) have been developed for predicting the global solar radiation in Minna, using computer software (IBM SPSS 20) programme. However, based on the highest values of correlation coefficient, R, coefficient of determination, $\mathrm{R}^{2}$, and lowest value of root mean square error, RMSE, model 7 which combined all the met data for this study, produced the best approximation to the measured solar radiation for the entire months of the year. The highest and lowest values of solar radiation $\left(18.28\left(\mathrm{MJm}^{-2} \mathrm{day}^{-1}\right)\right.$ and 14.58 $\left(\mathrm{MJm}^{-2} \mathrm{day}^{-1}\right.$ respectively), were obtained in the months of November and August, respectively, using model 7:

$\frac{\bar{H}}{\bar{H} O}=0.689+0.084\left(\frac{\bar{n}}{\bar{N}}\right)-0.023(\bar{R})-0.007(\bar{W})+0.115(\overline{R H})-0.357(\theta)-0.006\left(\frac{\bar{n}}{\bar{N}} * \bar{R} * \bar{W} * \overline{R H} * \theta\right)$

The models developed in this study could be applied to other locations having similar weather conditions as Minna.

\section{Acknowledgements}

Our thanks go to the management and staff of Nigerian Meteorological Agency, Minna, for providing us with the met data used in this study.

\section{References}

[1] A.O.C. Nwokoye, Solar energy technology: other alternative energy resources and environmental science (Rex Charles and Patricks Ltd, Nimo, 2006).

[2] A.G. Aliyu and A.S. Sambo, Development of a model for computing the total component of solar radiation in Sokoto, Nig. J. Ren. Energy, 2 (2), 1991, $10-17$.

[3] M. Bindi and F. Miglietta, Estimating daily global radiation from air temperature and rainfall measurements, Clim.Res 1, 1991,117 - 124 .

[4] F.O. Akinbode, Solar radiation in Minna: Correlation with meteorological data, Nig. J.Ren. Energy. 3 (1\&2), 1992,9 - 17.

[5] E.E. Iheonu, Model for the prediction of average monthly global solar radiation on a horizontal surface for some locations in the tropics using temperature data, Nig. J. Ren. Energy, 9 (1\&2), 2001,12-15.

[6] F.W. Burari and A.S. Sambo, Models for the prediction of global solar radiation for Bauchi using meteorological data, Nig. J. Ren. Energy. 9(1\&2), 2001, 30-33.

[7] E.J. Bala, Analysis of some meteorological data for four cities in the North Western Zone of Nigeria, Nig. J. Ren. Energy 9 (1\&2), 2001, 37 $-41$.

[8] L.E. Akpabio and S.E. Etuk, Relationship between global solar radiation and sunshine duration for Onne, Nigeria, Turk J. Phys, 27, 2003, $161-167$.

[9] Y.A. Sanusi, Ranking of the performance of some climatological parameters in the estimation of solar radiation in the Minna environment, Central Nigeria, Nig. J. Ren. Energy, 12 (1 \& 2), 2004, 27 - 37.

[10] L.E. Akpabio, S.O. Udo and S.E. Etuk, Modeling global solar radiation for a tropical location: Onne, Nigeria, Turk J. Phys., 29, 2005, 63 68.

[11] I.T. Togrul, Estimation of solar radiation from Angstroms coefficients by using geographical and meteorological data in Bishkek, Kyrgyzstan, J. Therm. Sc. Tech., 29 (2), 2009, $99-108$.

[12] C. Augustine and M.N. Nnabuchi, Analysis of some meteorological data for some selected cities in the Eastern and Southern zone of Nigeria, African J. Environ. Sc. Tech., 4 (2), 2010, 92 - 99.

[13] D.W. Medugu, A.B. Adisa, F.W. Burari and M.A. Abdul'Azeez, Solar radiation: Correlation between measured and predicted values in Mubi, Nigeria, Int. J. Sc. Tech. Ed. Res., 4 (1), 2013, 11 - 17.

[14] J.C. Ododo, In OAU/STRC Conference Proceedings: $2^{\text {nd }}$ OAU/STRC Conference on New, Renewable and Solar Energies, at Bamako Mali, 1994.

[15] J.A. Prescott, Evaporation from a water surface in relation to solar radiation, Tran. R. Soc. S. Austr., 64, $1940,114-118$

[16] M. Igbal, An Introduction to Solar Radiation (Academy Press: New York, 1983).

[17] A.A. El-Sebaii and A.A. Trabea, Estimation of global solar radiation on horizontal surfaces over Egypt, Egypt J. Solids, 2005,28 - 166. 